\title{
Keeping Pace with Adolescent Asthma: A Practical Approach to Optimizing Care
}

\author{
Zai Ru Cheng (D) - Yi Hua Tan · Oon Hoe Teoh · Jan Hau Lee
}

Received: September 12, 2021 / Accepted: October 25, 2021 / Published online: November 6, 2021

(c) The Author(s) 2021

\begin{abstract}
Known for their pre-occupation with body image, self-identity creation, peer acceptance, and risk-taking behaviors, adolescents with asthma face unique challenges. Asthma is a heterogeneous disease and accurate diagnosis requires assessment through detailed clinical history, examination, and objective tests. Diagnostic challenges exist as many adolescents can present with asthma-like symptoms but do not respond to asthma treatment and risk being mis-diagnosed. Under-recognition of asthma symptoms and denial of disease severity must also be addressed. The over-reliance on shortacting beta-agonists in the absence of anti-inflammatory therapy for asthma is now deemed unsafe. Adolescents with mild asthma benefit from symptom-driven treatment with combination inhaled corticosteroids (ICS) and longacting beta-agonist (LABA) on an as-required
\end{abstract}

Z. R. Cheng $(\varangle) \cdot$ Y. H. Tan · O. H. Teoh

Department of Paediatrics, Respiratory Medicine Service, KK Women's and Children's Hospital, 100 Bukit Timah Road, Singapore 229899, Singapore e-mail: cheng.zai.ru@kkh.com.sg

J. H. Lee

Department of Paediatric Sub-Specialties, Children's Intensive Care Unit, KK Women's and Children's Hospital, Singapore, Singapore

Y. H. Tan · O. H. Teoh · J. H. Lee

Duke-NUS Medical School, Singapore, Singapore basis. For those with moderate-to-persistent asthma requiring daily controller therapy, maintenance and reliever therapy using the same ICS-LABA controller simplifies treatment regimes, while serving to reduce exacerbation risk. A developmentally staged approach based on factors affecting asthma control in early, middle, and late adolescence enables better understanding of the individual's therapeutic needs. Biological, psychological, and social factors help formulate a risk assessment profile in adolescents with difficult-to-treat and severe asthma. Smoking increases risks of developing asthma symptoms, lung function deterioration, and asthma exacerbations. Morbidity associated with e-cigarettes or vaping calls for robust efforts towards smoking and vaping cessation and abstinence. As adolescents progress from child-centered to adult-oriented care, coordination and planning are required to improve their self-efficacy to ready them for transition. Frequent flare-ups of asthma can delay academic attainment and adversely affect social and physical development. In tandem with healthcare providers, community and schools can link up to help shoulder this burden, optimizing care for adolescents with asthma.

Keywords: Adolescents; Asthma; Smoking; Transition 


\section{Key Summary Points}

Adolescents with asthma face unique challenges, exacerbated by their preoccupation with body image, self-identity creation, need for peer acceptance, and risk-taking behaviors.

Diagnostic conundrums exist in asthma and reliance on a good clinical history, physical examination, objective tests, and response to treatment assessed over time is crucial for an accurate diagnosis.

Understanding an adolescent according to their stage of development in early, middle, and late adolescence can help formulate risk factors and protective mechanisms in their asthma care.

Biological, psychological, and social factors affect an adolescent with difficultto-treat and severe asthma.

Transition of care to adult-oriented settings is a planned and coordinated process based upon the individual's level of self-efficacy and should not be orchestrated out of physician frustration.

\section{INTRODUCTION}

The 'waters of adolescence' are navigated by individuals $10-19$ years old [1]. Up to $12 \%$ of adolescents worldwide suffer from chronic disease [2] and asthma continues to afflict this age group. Widely considered a disease of childhood with reduction in symptom flare-ups with age [3], adolescents still experience significant asthma morbidity [4] due to unique challenges posed whilst entering this phase and during transition to adult care [5]. Peer acceptance, selfidentity, and experimentation form a web of psychosocial factors that interlace with the biological changes of puberty to have a profound impact on adolescent health and wellbeing [6]. This necessitates the adoption of a developmentally staged management approach in adolescents with asthma [7]. This narrative review discusses diagnostic conundrums, pitfalls associated with over- and under-reporting of asthma symptoms, and the impact of developmental stages on adolescent asthma control. Factors associated with difficult-to-treat and severe asthma in adolescence and blind spots during transition to adult-oriented care are also highlighted. This article is based on reviews of current guidelines and literature and did not involve any new studies with human participants or animals performed by any of the authors.

\section{CONUNDRUMS ASSOCIATED WITH DIAGNOSING ADOLESCENT ASTHMA}

Table 1 lists common mimickers of asthma in an adolescent. Asthma is highly heterogeneous and symptoms and control vary with the passage of time [8], on the back of a multitude of triggers [9]. Diagnostic uncertainty can arise when an asthmatic child does not demonstrate significant spirometry bronchodilator reversibility (increase in forced expiratory volume in $1 \mathrm{~s}$ (FEV1) by $\geq 12 \%$ ), especially if baseline pre-bronchodilator lung function test is normal [10]. The gathering of supportive evidence for asthma (e.g., response to previous inhaled corticosteroids (ICS) therapy, self-reported bronchodilator response and atopic status) over time may increase diagnostic confidence.

Of particular interest in adolescents, patients who report breathlessness and noisy breathing during rest or exercise may have inducible laryngeal obstruction (ILO) [11]. ILO that occurs during exercise can be due to exercise-induced laryngeal obstruction (EILO) [12]. This oft-under-recognized entity presents with inspiratory stridor, throat tightness, maximal breathlessness during exertion and resolution upon rest [13], or changes in voice post-exercise [14]. EILO often affects elite athletes between 11 and 18 years old, especially those with underlying anxious personalities $[15,16]$. Diagnosing EILO involves continuous fiber-optic laryngoscopy 


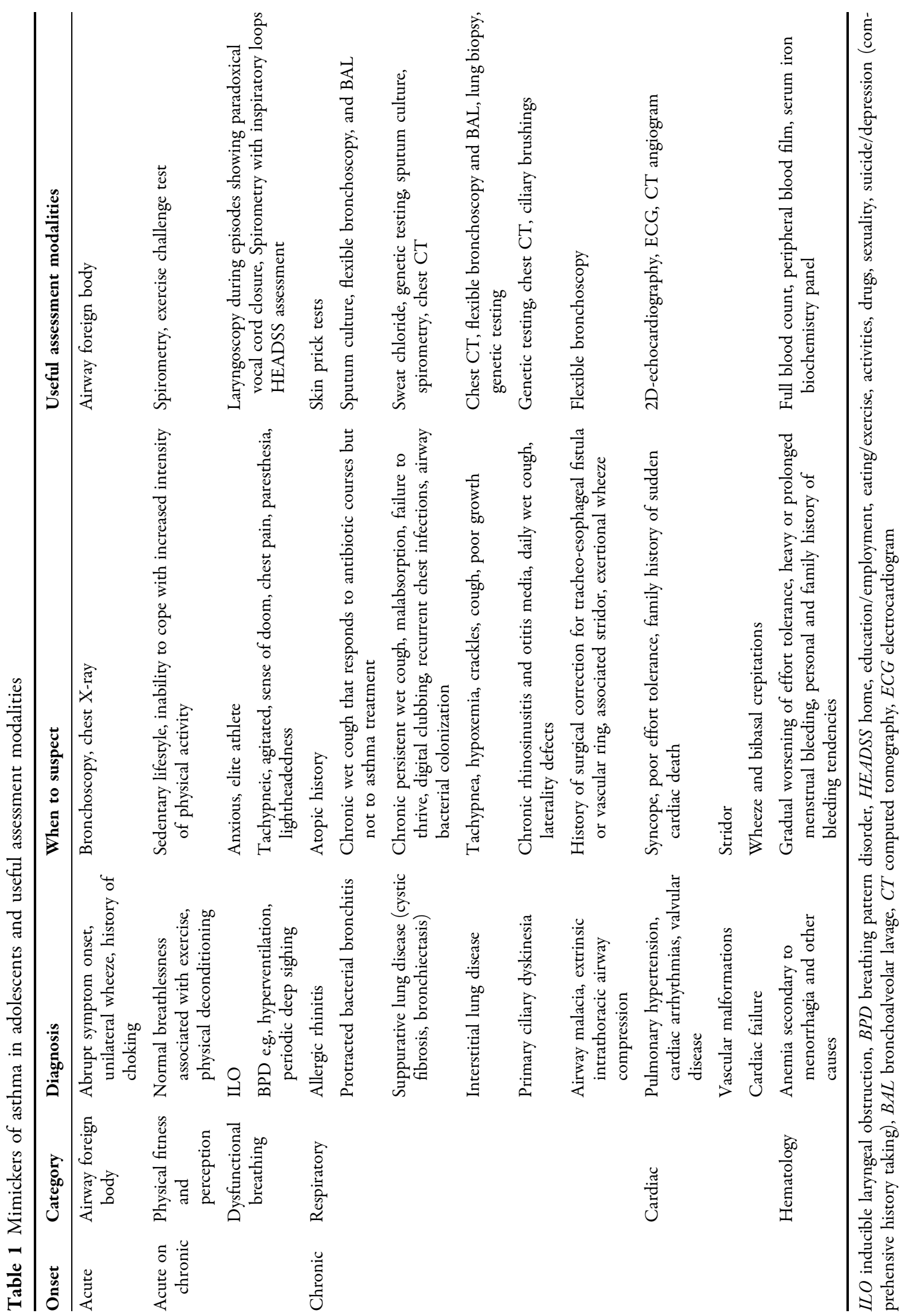


during exercise to visualize inappropriate laryngeal closure [17]. Few are accustomed or willing to tolerate this. EILO is often confused with exercise-induced bronchospasm (EIB), which requires a fall in FEV1 $\geq 10 \%$ and $>200 \mathrm{ml}$ from baseline during an exercise challenge test [18]. These two conditions rarely co-exist [19] and have distinct clinical features [20] (Table 2).

\section{OVER- AND UNDER-REPORTING OF ASTHMA SYMPTOMS: RECOGNIZING AND ADDRESSING PITFALLS}

Discrepancy can exist between perceived severity of symptoms and clinical assessments. Occasionally, reported "severe" symptoms are attributed to psycho-somatic manifestations in adolescents when objective assessments for asthma diagnosis are non-corroborative and response to treatment inconsistent [21]. The interplay between chronic disease and psychosocial functioning [22] must be discussed with the family and recognized as a potential contributor to erroneous symptom attribution or hyper-vigilance to asthma-related emotional cues of stress and anxiety [23].

Conversely, under-recognition of asthma severity occurs more commonly in adolescents. Some adolescents normalize and accept their chronic asthma symptoms over time, while others adopt coping strategies (e.g., minimizing physical activity). Some under-report asthma symptoms or reliever medication use to avoid escalation of their controller therapy. As such, reversible airway obstruction and airway inflammation are often demonstrated on objective tests even when the patient reports no symptoms. The asthma control review should be done in a non-judgmental manner, involving a mix of open-ended questions and specific clarifications. Where available, the addition of regular lung function tests adds objectivity to the assessment of asthma control and severity (Table 3 ).

Adolescents prescribed daily ICS are often non-concordant [24]. The need for different inhaler devices for both controller and reliever therapies adds to this problem. A major change in the Global Initiative for Asthma (GINA) [25] 2019 guidelines paved the way for adolescents with mild asthma to choose between daily low dose ICS or as-needed symptom-driven use of ICS combined with long-acting beta-agonist (LABA) in the form of budesonide-formoterol Symbicort ${ }^{\circledR}$ dry powder inhaler (DPI). This change was supported by the results of the 'SYmbicort Given as needed in Mild Asthma' (SYGMA-2) trial [26, 27], which showed non-inferiority of budesonide-formoterol DPI as a reliever for the rate of annualized severe asthma exacerbations in patients $\geq 12$ years, compared to maintenance low-dose budesonide with asrequired short-acting beta-agonists (SABA). Asneeded treatment with budesonide-formoterol was shown to prevent exacerbations and significantly reduced median daily ICS dose. The preceding SYGMA-1 [28] trial also showed that asneeded budesonide-formoterol combination was superior to as-needed terbutaline for asthma symptom control and prevention of exacerbations. This heralded a fundamental shift away from solely using as required SABA in mild asthma, a practice now deemed unsafe [29].

Adolescents aged $\geq 12$ years with moderateto-severe persistent asthma require daily controller therapy. Following the evolution of guidelines up to GINA 2021, there are currently two treatment tracks to choose from: budesonide-formoterol prescribed in a single inhaler for use in both 'Maintenance And Reliever Therapy' (MART), or higher-dose ICS-LABA as controller and SABA for reliever [30]. An asthma action plan based on MART that escalates treatment using the same controller inhaler based on self-recognition of symptoms is welcomed from a patient perspective [31]. MART reduces exacerbation risk that continues to exist even in the mildest of asthma phenotypes, simplifying treatment regimens and reducing acute care visits [32].

\section{DIFFICULT-TO-TREAT AND SEVERE ASTHMA DURING ADOLESCENCE}

Asthma may seem "difficult to treat" due to modifiable factors of poor adherence, smoke 
exposure, co-morbidities, or incorrect diagnosis (Table 1). Table 4 lists predisposing factors for poor asthma control, protective factors [33] and helpful strategies across the adolescent trajectory in the three developmental stages of early, middle, and late adolescence [34-47].

The advent of biologics over the past decade has provided an alternative treatment option to steroid-dependent uncontrolled asthmatics [48]. The first widely used agent, omalizumab, initially targeted at children $\geq 12$ years, is currently approved for use in children $\geq 6$ years old. It is indicated as add-on therapy in severe asthmatics with elevated immunoglobulin-E (IgE) levels, inadequately controlled on ICS, with aeroallergen sensitization [49]. Omalizumab is a humanized monoclonal antibody that binds selectively to IgE and involves 2-4 weekly subcutaneous administration. It has been demonstrated to improve asthma symptom control, reduce exacerbations, and minimize the need for systemic corticosteroids [50]. A course of omalizumab is long drawn and its efficacy on asthma control after cessation has been evidenced to span at least 4 years in $60 \%$ of adult patients who voluntarily discontinued omalizumab after 6 years of therapy [51]. However, this finding has yet to be substantiated in pediatric studies. In view of its substantial cost and sporadic adverse effects that include risks of anaphylaxis and malignancy, initiation of omalizumab for severe asthmatics requires careful consideration under specialist review. A review of such biologics therapy is recommended if the patient is deemed clinically unresponsive after 16 weeks [52]. Omalizumab has nevertheless been proven to be safe and well tolerated in children [53], even with treatment duration beyond 2 years [54]. Mepolizumab (targets interleukin-5) and dupilumab (antibody to interleukin-4) were more recently approved for children with refractory eosinophilic asthma [55].

Adolescents with asthma who remain uncontrolled despite treatment concordance and mitigation of risk factors or worsen upon reduction of high-dose treatment are termed "severe" [56]. Recognizing biological, psychological, and social risk factors can help formulate a risk assessment profile in the process of delivering individualized care (Table 5).

Table 2 Key features differentiating EILO and EIB. Table adapted from [12]

\begin{tabular}{lcc}
\hline Key presenting features & EILO & EIB \\
\hline Chest tightness & \pm & + \\
Throat tightness & + & - \\
Inspiratory stridor & - & + \\
Expiratory wheeze & Aerobic exercise, hot or cold temperatures, airway \\
Usual triggers & irritation, extreme emotion \\
& GERD, post-nasal drip & Allergens \\
Co-morbidities & Usually single trigger & Usually many \\
Number of triggers & $<5$ & $>5-10$ \\
Usual onset of symptoms after initiation of physical activity (min) & $5-10$ & $15-60$ \\
Recovery period (min) & - & + \\
Bronchodilator response or improvement with systemic corticosteroids & - & -
\end{tabular}

EIB Exercise-induced bronchospasm, GERD Gastro-esophageal reflux disease 
Table 3 Lung function tests with utility for assessment of adolescents with asthma

\begin{tabular}{ll}
\hline Name of test & Results supporting variable expiratory airflow limitation \\
\hline Spirometry & Low FEV1 with FEV1/FVC ratio below lower limit of normal (in children, $<0.9)$ \\
& FEV1 increases from pre-bronchodilator value by $\geq 12 \%$ \\
Exercise challenge test & Fall in FEV1 of $\geq 10 \%$ and $>200 \mathrm{ml}$ from baseline \\
\hline
\end{tabular}

\begin{tabular}{ll}
\hline & Results supporting airway inflammation \\
\hline $\mathrm{FeNO}$ & $>25 \mathrm{ppb}$
\end{tabular}

$\overline{F E V 1 \text { forced expiratory volume in } 1 \mathrm{~s}, F V C \text { forced vital capacity, } F e N O \text { fractional exhaled nitric oxide, } p p b \text { parts per billion }}$

Biological factors associated with greater risk of cardio-respiratory morbidity and mortality include poor lung function with severely impaired airflow obstruction, commonly taken as FEV $1<60 \%$ predicted $[57,58]$. Predisposition towards impaired lung function in adulthood includes past admissions to intensive care for asthma [59], over-usage of reliever medications, increased airway variability, and low baseline FEV1 [60]. In a Swedish birth cohort study analyzing body mass index (BMI) development throughout childhood in relation to the timing of asthma onset and remission, the persistence of asthma from childhood up to 18 years of age was temporally associated with high BMI amongst females, whereas girls without asthma had the lowest BMI throughout most of their childhood. This indicates that there are overlapping risk factors for being overweight and asthmatic, starting even from infancy [61]. Weight loss interventions such as diet and exercise improve asthma-related quality of life and control in studies conducted across obese pediatric and adult groups [62] and such measures should be openly discussed from an early age. Other factors such as increased blood eosinophilia at asthma diagnosis favorably predicted resolution of severe asthma during adolescence [63].

Psychological factors and mental health play a big role in asthma outcomes. The prevalence of psychiatric comorbidities (e.g., depression and anxiety) is higher in adolescents with asthma; and quality of life and asthma control tend to be poorer when psychiatric disorders and asthma co-exist [64]. Vulnerability of the immune system related to psychological disorders can also lead to greater exacerbation risks [65]. Psychosocial stressors (e.g., poverty, violence, racism, and discrimination) adversely impact an adolescent's asthma control. Stress exerts direct effects via a pro-inflammatory physiological state, while indirect mechanisms are attributed to risky behaviors involving sex, cigarette smoking, alcohol, substance use, and poor dietary choices [66].

Social factors, such as disorganized home environments, worsen asthma control [67]. Initiating timely support during periods of family chaos or breakdown in peer relationships [68] can steer the maladjusted adolescent away from harm. Exposure to household tobacco smoke and peer smokers influence the initiation and maintenance of smoking in adolescents with asthma [69], who model after their closest contacts.

\section{SMOKING}

Individuals who smoke have a higher risk of developing asthma symptoms [70], have poorer lung function [71], and asthma flare-ups [72]. In a Brazilian study involving over 66,000 adolescents, smoke exposure amongst adolescents remains high with rates of $12-28 \%$ [73]. E-cigarette use amongst high-school teens in the United States reached $19.7 \%$ in 2020 , with the majority sourcing vaping products from friends [74]. Morbidity attributed to e-cigarette or 


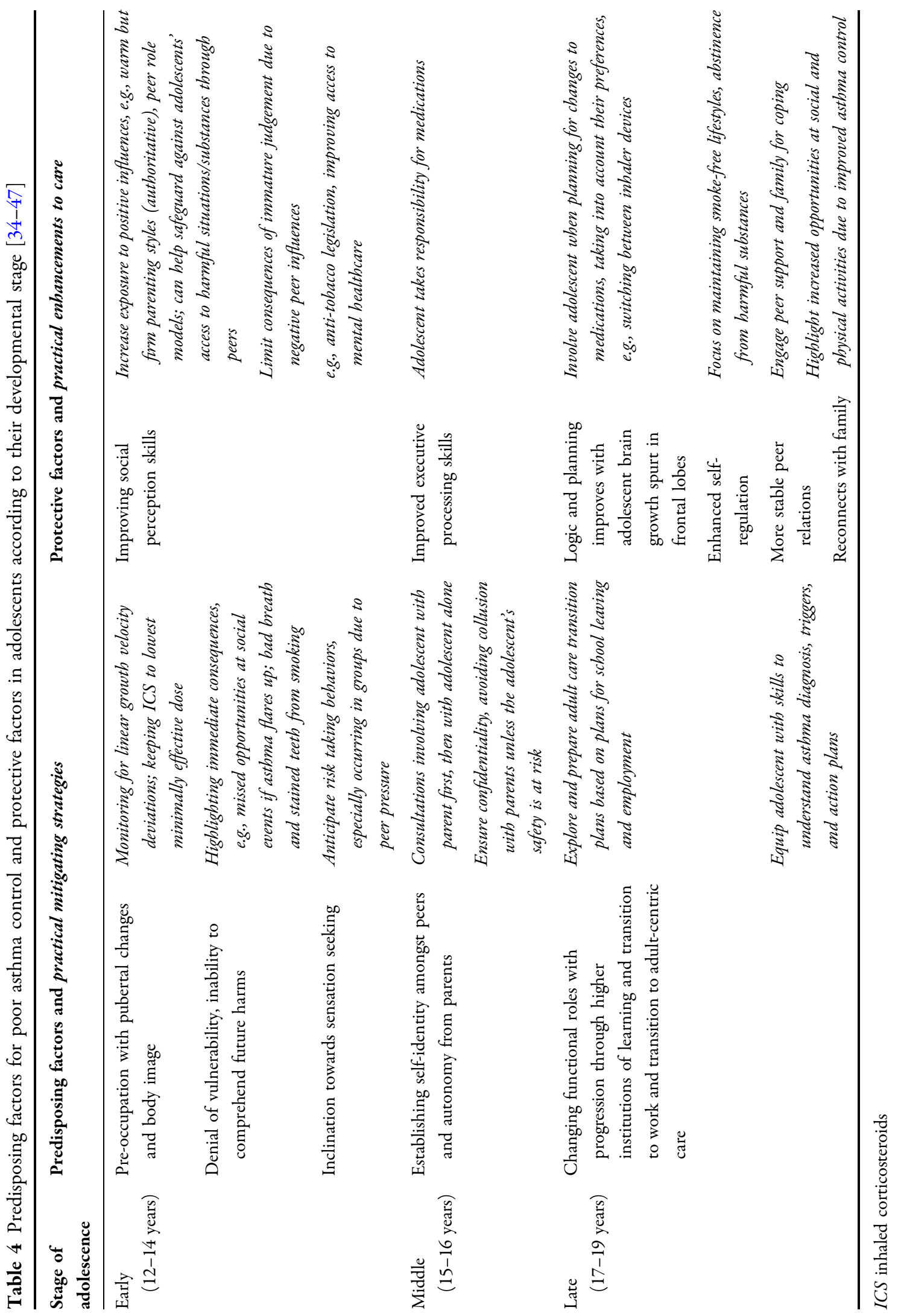


vaping product use-associated lung injury (EVALI) further compounds their dangers [75]. In the largest known case series of 98 EVALI patients (median age 21 years, range 15-53 years), most patients presented with multisystemic involvement including respiratory, gastrointestinal, and constitutional symptoms. Notably, despite the majority having no significant past medical history other than asthma, $53 \%$ of patients required intensive care for respiratory failure [76]. Worrisome data from this cluster outbreak called for abstinence from e-cigarette use and greater awareness of its harms to avoid a rising national epidemic, resulting in a decline of cases in the United States, after peaking in September 2019 [77].

Comparatively, smoking-cessation measures are not as well studied in adolescents compared to adults [78]. Adolescents are a notoriously challenging group to enroll into formal smoking-cessation programs and have high dropout rates [79]. In a systematic review conducted involving 41 studies that recruited young people under 20 years, investigators found that beyond group-based counselling programs, other behavioral-support measures or smoking-cessation pharmacotherapeutics in young people have yet to show longterm efficacy [80]. This calls for more well-designed and adequately powered studies to advance adolescent smoking-cessation treatment programs. Nevertheless, environmental smoke exposure in a home setting is a modifiable risk factor for asthma in adolescents [81]. Smoking-cessation techniques employing motivational interviewing and cognitive behavioral techniques [82] are potentially useful if adapted to an adolescent's level of understanding. Adolescents are likely more susceptible than chronically smoking adults to experience rapid onset of nicotine dependence, occurring within 1 month of initiation [83]. This makes the process of quitting even more challenging. Nicotine dependence is best quantified by time to first cigarette upon waking and number of cigarettes smoked per day as part of the Fagerström test [84]. The 5As (Ask, Advise, Assess, Assist, Arrange) of smoking-cessation counselling are effective in smoking prevention and abstinence when modified for adolescents [85].

Financial incentives with free cessation aids were proven to be more efficacious than usage of cessation aids alone, in employees up to 1-year post enrolment into smoking-cessation programs [86]. Incentivizing smoking cessation with vouchers rides on the developing adolescent brain's heightened response to rewardseeking [87], outweighing the thrills sought from smoking.

\section{ADDRESSING BLIND SPOTS IN TRANSITION OF CARE}

Transitioning from child-centric to adult-oriented care requires planning and coordination [88]. Successful established pathways such as 'Ready Steady Go' initiated within the National Health Service, United Kingdom [89], begins this staged process from age 11 years old, with generic patient and parent questionnaires applicable across all specialties [90]. Caregivers' and patients' disease knowledge and attitudes must first be addressed, followed by empowering the young person with self-help skills, all of which requires multidisciplinary healthcare support [91]. Best practices for transitional health care include appropriate parental involvement and promotion of the adolescents' self-efficacy in managing their health [92]. Adopting a flexible approach in the culmination to adult-oriented care from 16 to 19 years old onwards takes into consideration their transition readiness, school-leaving plans, and varied levels of self-efficacy [93]. Reaching this milestone in care should not be reliant on chronological age alone or orchestrated out of physician frustration towards an adolescent with difficult to control asthma [94]. An oppositional adolescent allowed to "drop out" of the healthcare system faces missed opportunities in addressing risks for severe exacerbations [95]. Generally, asthmatic adolescents who do not require daily medications can be transited to primary healthcare whilst some may require a specialist referral for shared care [96]. Those requiring daily medications with greater disease burden and family vulnerabilities can be transited to the adult respiratory specialist equipped with multi-disciplinary resources such as a specialist nurse practitioner trained in adolescent care to facilitate the process [97]. During this 
Table 5 Risk assessment profile for difficult to control adolescent asthma

\begin{tabular}{|c|c|c|}
\hline Biological & Psychological & Social \\
\hline $\begin{array}{l}\text { - Severely impaired lung function } \\
\text { - Past ICU admissions } \\
\text { - Over-usage of bronchodilators } \\
\text { - Frequent acute-care visits } \\
\text { - Early sensitization } \\
\text { - Lower bronchodilator response } \\
\text { - Increased airway variability } \\
\text { - Obesity } \\
\text { - Higher blood eosinophilia (prognostic factor for } \\
\text { resolution of severe asthma in adolescence) }\end{array}$ & $\begin{array}{l}\text { - Depression, anxiety, } \\
\text { neurodevelopmental } \\
\text { conditions } \\
\text { - Chronic stress } \\
\text { - Pro-inflammatory } \\
\text { - Risk-taking behaviors } \\
\text { - Poor dietary and lifestyle } \\
\text { choices } \\
\text { - Poor adherence }\end{array}$ & $\begin{array}{l}\text { - School } \\
\text { - Breakdown in peer } \\
\text { relationships } \\
\text { - Family chaos } \\
\text { - Conflict } \\
\text { - Disorganized routines } \\
\text { - Breakdown in parent-child } \\
\text { communication } \\
\text { - Smoke exposure within } \\
\text { homes and from peers }\end{array}$ \\
\hline
\end{tabular}

$I C U$ intensive care unit

challenging pandemic, telemedicine has become integral to asthma care to allow continued engagement and adherence to outpatient appointments [98]. Furthermore, joint video consultations [99] with pediatric and adult medical practitioners can help orientate the patient amidst movement restrictions across institutions. However, for families unfamiliar with telemedicine, the option to switch to faceto-face visits should always still be made available to them. Care should be taken to avoid loading already-burdened families of chronic disease patients with the stress of partaking in technology that may remain inaccessible to them [100].

\section{FUTURE DIRECTIONS IN CARING FOR ADOLESCENTS WITH ASTHMA AND CONCLUDING REMARKS}

The management of adolescent asthma should be supported by population, community- and school-based strategies in tandem with the efforts of healthcare providers (Fig. 1). Marketing efforts by tobacco-sponsored industry increase the youth's susceptibility to smoking [101]. Raising the minimum legal age for sale of tobacco and e-cigarette products from 18 to 21 years [102] and launching youth e-cigarette prevention campaigns [103] are helpful counter-marketing measures [104]. School-based [105] and peer-led programs [106] have provided beneficial support for adolescents with asthma. Self-perceived under-performance in school and lack of participation in physical activities are more likely in asthmatics than in others [107]. As the burden of chronic disease competes with academic attainment, schools and healthcare teams must link up [108], aiming to minimize school absenteeism attributed to appointments and flare-ups. Whilst asthma health technology [109] is eagerly embraced by adolescents, more evidence is required in proving that applications [110] for medication adherence, disease monitoring, and health literacy are effective. Human-computer interactions for inhaler technique competency, peak flow monitoring, and medication reminders are promising and complement current practices $[111,112]$ but require further patient engagement to fulfil unmet needs [113].

A rewarding experience awaits as we journey with adolescents from asthma diagnosis to adult transition. Continued engagement with schools and communities can provide a safer springboard for individuals leaving childhood into adolescence, as they transition towards better asthma outcomes in adulthood. 


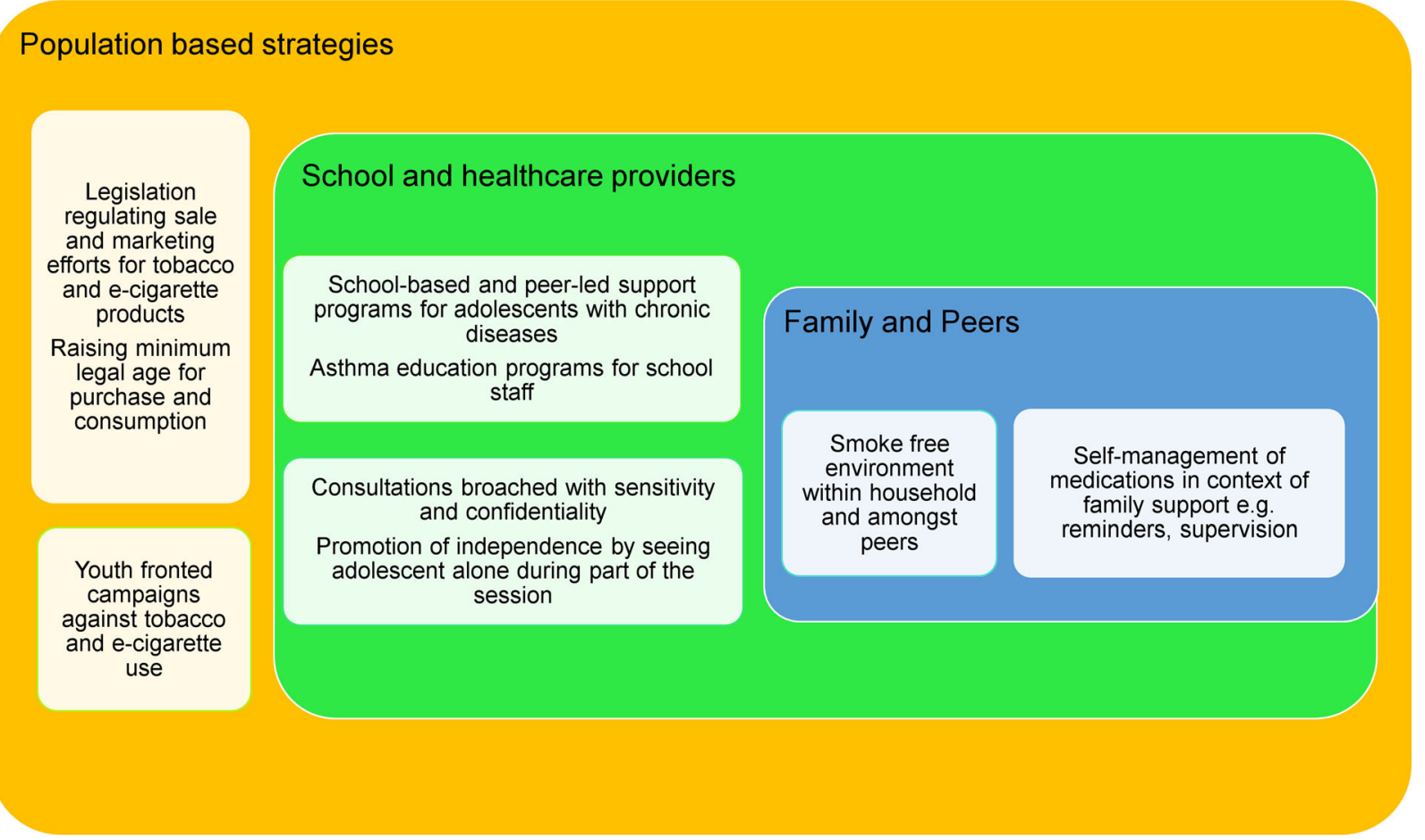

Fig. 1 Levels of care in holistic asthma management for adolescents. Levels of asthma care range from large-scale population-based strategies to smaller-scale school and

\section{ACKNOWLEDGEMENTS}

Funding. No funding or sponsorship was received for the publication of this article.

Authorship. All named authors meet the International Committee of Medical Journal Editors (ICMJE) criteria for authorship for this article, take responsibility for the integrity of the work as a whole, and have given their approval for this version to be published.

Author Contributions. Zai Ru Cheng: conceptualization, writing- original draft, visualization, project administration. Yi Hua Tan: writing- review and editing, supervision. Oon Hoe Teoh: writing- review and editing, supervision. Jan Hau Lee: writing- review and editing, supervision, resources, project administration. healthcare providers' efforts, followed by specific familyand peer-support measures

Disclosures. Zai Ru Cheng, Yi Hua Tan, Oon Hoe Teoh, and Jan Hau Lee have nothing to disclose.

Compliance with Ethics Guidelines. This article is based on reviews of current guidelines and literature and did not involve any new studies with human participants or animals performed by any of the authors.

Open Access. This article is licensed under a Creative Commons Attribution-NonCommercial 4.0 International License, which permits any non-commercial use, sharing, adaptation, distribution and reproduction in any medium or format, as long as you give appropriate credit to the original author(s) and the source, provide a link to the Creative Commons licence, and indicate if changes were made. The images or other third party material in this article are included in the articleöûus Creative Commons licence, unless indicated otherwise in a credit line to the material. If 
material is not included in the articleöûus Creative Commons licence and your intended use is not permitted by statutory regulation or exceeds the permitted use, you will need to obtain permission directly from the copyright holder. To view a copy of this licence, visit http://creativecommons.org/licenses/by-nc/4. $0 /$.

\section{REFERENCES}

1. World Health Organization. Health for the world's adolescents: a second chance in the second decade: summary. Geneva. WHO Headquarters; 2014. 14p. Report No.: WHO/FWC/MCA/14.05. Available from: https://ahpsr.who.int/publications/i/item/ health-for-the-world-s-adolescents-a-secondchance-in-the-second-decade-summary. [cited 2021 Sep 9]

2. Sawyer SM, Drew S, Yeo MS, Britto MT. Adolescents with a chronic condition: challenges living, challenges treating. Lancet. 2007;369:1481-9.

3. Nicolai T, Illi S, Tenborg J, Kiess W, Mutius EV. Puberty and prognosis of asthma and bronchial hyper-reactivity. Pediatr Allergy Immunol. 2001;12(3):142-8.

4. Levy ML, Andrews R, Buckingham R, et al. Royal College of Physicians. Why asthma still kills: the National Review of Asthma Deaths Confidential Enquiry report. London: Healthcare Quality Improvement Partnership; 2014. p. 19p.

5. Global Initiative for Asthma. Global strategy for Asthma management and prevention, 2020 update. GINA; 2020. 174p. Available from: https:// ginasthma.org/archived-reports/. [accessed 2021 May 5]

6. Patton GC, Viner R. Pubertal transitions in health. Lancet. 2007;369:1130-9.

7. Sadoff M, Kaslovsky R. Adolescent asthma: a developmental approach. Curr Opin Pediatr. 2011;23: 373-8.

8. Dharmage SC, Perret JL, Custovic A. Epidemiology of asthma in children and adults. Front Pediatr. 2019;7:246.

9. National Institute for Health and Care Excellence. Asthma: diagnosis, monitoring and chronic asthma management. United Kingdom. National Institute for Health and Care excellence, 2021. Published
Nov 2017, updated March 2021. 39p. Available from: www.nice.org/uk/guidance/ng80

10. Tse SM, Gold DR, Sordillo JE, et al. Diagnostic accuracy of the bronchodilator response in children. J Allergy Clin Immunol. 2013;132(3):554-9.

11. Halvorsen T, Walsted ES, Bucca C, et al. Inducible laryngeal obstruction: an official joint European Respiratory Society and European Laryngological Society statement. Eur Respir J. 2017;50:1602221. https://doi.org/10.1183/13993003.02221-2016.

12. Welsh L, Giannini A, Massie J. Exercise-induced laryngeal obstruction in children and adolescents: are we listening? Arch Dis Child Educ Pract Ed. 2020;106:66-70.

13. Hull JH. Not all wheeze is asthma: time for patients to exercise their rights. Thorax. 2015;70:7-8.

14. Morris M, Christopher KL. Diagnostic criteria for the classification of Vocal Cord Dysfunction. Chest. 2010;138(5):1213-23.

15. Simon NM, Weiss AM, Kradin R, et al. The relationship of anxiety disorders, anxiety sensitivity and pulmonary dysfunction with dyspnea-related distress and avoidance. J Nerv Ment Dis. 2006;194(12):951-77.

16. Nielsen EW, Hull JH, Backer V. High prevalence of exercise-induced laryngeal obstruction in athletes. Med Sci Sports Exerc. 2013;45(11):2030-5.

17. Weinberger M, Hasan MA. Pseudo-asthma: when cough, wheezing and dyspnea are not asthma. Pediatrics. 2007;120:855-64.

18. Hallstrand TS, Leuppi JD, Joos G, et al. ERS technical standard on bronchial challenge testing: pathophysiology and methodology of indirect airway challenge testing. Eur Respir J. 2018;52:1801033.

19. Li RC, Singh U, Windom HP, Gorman S, Berstein JA. Clinical associations in the diagnosis of vocal cord dysfunction. Ann Allergy Asthma Immunol. 2016;117:354-8.

20. Sandage MJ, Zelazny SK. Paradoxical vocal fold motion in children and adolescents. Lang Speech Hear Serv Sch. 2004;35:353-62.

21. Towns SJ, Asperen PP. Diagnosis and management of asthma in adolescents. Clin Respir J. 2009;3: 69-76.

22. Hallstrand TS, Curtis JR, Aitken ML, Sullivan SD. Quality of life in adolescents with mild asthma. Pediatr Pulmonol. 2003;36(6):536-43. 
23. Lieshout R, MacQueen G. Psychological factors in asthma. Allergy Asthma Clin Immunol. 2008;4(1): 12-28.

24. Murphy J, McSharry J, Hynes L, Matthews S, Van Rhoon L, Molloy GJ. Prevalence and predictors of adherence to inhaled corticosteroids in young adults (15-20 years) with asthma: a systematic review and meta-analysis. J Asthma. 2020;58: 683-705.

25. Global Initiative for Asthma. 2019 Pocket guide for asthma management and prevention. GINA; 2019. 39p. Available from: https://ginasthma.org/ archived-reports/. [accessed 2021 Jun 6]

26. Bateman ED, Reddel HK, O'Byrne PM, et al. Asneeded budesonide-formoterol versus maintenance budesonide in mild asthma. $\mathrm{N}$ Engl J Med. 2018;378:1877-87.

27. Rajan S, Gogtay NJ, Konwar M, Thatte UM. The global initiative for asthma guidelines (2019): change in the recommendation for the management of mild asthma based on the SYGMA- 2 triala critical appraisal. Lung India. 2020;37(2):169-73.

28. O'Byrne P, FitzGerald M, Bateman E, Barnes P. Inhaled combined budesonide-formoterol as needed in mild asthma. N Engl J Med. 2018;378: 1865-76.

29. Reddel HK, FitzGerald JM, Bateman ED, et al. GINA 2019: a fundamental change in asthma management. Eur Respir J. 2019;53:1901046.

30. Global Initiative for Asthma. 2021 GINA report. GINA; 2021. Asthma treatment tracks for adults and adolescents. 3p. Available from: https://ginasthma. org/reports/. [accessed 2021 Aug 8]

31. Chapman KR, An L, Bosnic-Anticevich S, et al. Asthma patients' and physicians' perspectives on the burden and management of asthma. Respir Med. 2021;186: 106524. https://doi.org/10.1016/j. rmed.2021.106524.

32. Avery C, Perrin EM, Lang JE. Updates to the pediatrics asthma management guidelines. JAMA Pediatr. 2021;175(9):966-7.

33. Kim BKE, Oesterle S, Catalano RF, Hawkins JD. Change in protective factors across adolescent development. J Appl Dev Psychol. 2015;40:26-37.

34. Boyd D, Bee H. Lifespan development. Chapter 11, Physical and cognitive development in adolescence. 7th ed. Canada: Pearson; 2015. p. 265-316.

35. LaFontana K, Cillessen A. Developmental changes in the priority of perceived status in childhood and adolescence. Soc Dev. 2010;19(1):130-47.
36. Rosen DS. Pubertal growth and sexual maturation for adolescents with chronic illness or disability. Pediatrician. 1991;18(2):105-20.

37. Suris J, Michaud P, Viner R. The adolescent with a chronic condition. Part I: developmental issues. Arch Dis Child. 2004;89:938-42.

38. Zhang L, Lasmar LB, Castro-Rodriguez JA. The impact of asthma and its treatment on growth: an evidence-based review. J Pediatr (Rio J). 2019;95: S10-22.

39. Mercurio E, Garcia-Lopez E, Anyela L, et al. Adolescent brain development and progressive legal responsibility in the Latin American context. Front Psychol. 2020;11:627.

40. Newman K, Harrison L, Dashiff C, Davis S. Relationships between parenting styles and risk behaviours in adolescent health: an integrative literature review. Rev Lat Am Enfermagem. 2008;16(1): 142-50.

41. Xu F, Han Y, Sabbagh MA, Wang T, Ren X, Li C. Developmental differences in the structure of executive function in middle childhood and adolescence. PLoS One. 2013;8(10): e77779.

42. Segal TY. Adolescence: what the cystic fibrosis team needs to know. J R Soc Med. 2008;101:S15-27.

43. Withers AL. Management issues for adolescents with cystic fibrosis. Pulm Med. 2012;2012:13412.

44. Poulin F, Chan A. Friendship stability and change in childhood and adolescence. Dev Rev. 2010;30(3): 257-72.

45. Davies PL, Rose JD. Assessment of cognitive development in adolescents by means of neuropsychological tasks. Devl Neuropsych. 1999;15(2):227-48.

46. Luna B. Developmental changes in cognitive control through adolescence. Adv Child Dev Behav. 2009;37:233-78.

47. Steinberg L. A social neuroscience perspective on adolescent risk-taking. Dev Rev. 2008;28(1):78-106.

48. Huffaker MF, Phipatanakul W. Pediatric asthma: guidelines-based care, omalizumab and other potential biologic agents. Immunol Allergy Clin North Am. 2015;35(1):129-44.

49. US Food and Drug Administration. Xolair (omalizumab) US prescribing information. United States: FDA. Available at: https://www.accessdata.fda.gov/ drugsatfda_docs/label/2016/103976s5225lbl.pdf. [Updated $2016 \mathrm{Jul}]$ 
50. Chipps BE, Lanier B, Milgrom H, et al. Omalizumab in children with uncontrolled allergic asthma: review of clinical trial and real-world experience. J Allergy Clin Immunol. 2017;139:1431-44.

51. Vennera MC, Sabadell C, Picado C, et al. Duration of the efficacy of omalizumab after treatment discontinuation in 'real life' severe asthma. Thorax. 2018;73:782-4.

52. Chung KF, Wenzel SE, Brozek JL, et al. International ERS/ATS guidelines on definition, evaluation and treatment of severe asthma. Eur Respir J. 2014;43(2):343-73.

53. Rodrigo G, Neffen H. Systematic review on the use of omalizumab for the treatment of asthmatic children and adolescents. Pediatr Allergy Immunol. 2015;26(6):551-6.

54. Odajima H, Ebisawa M, Nagakura T, et al. Longterm safety, efficacy, pharmacokinetics and pharmacodynamics of omalizumab in children with severe uncontrolled asthma. Allergol Int. 2017;66(1):106-15.

55. Giovannini M, Mori F, Barni S, et al. Omalizumab and mepolizumab in the landscape of biological therapy for severe asthma in children: how to choose? Ital J Pediatr. 2019;45:151.

56. Global Initiative for Asthma. 2021 GINA report. GINA 2021. Difficult-to-treat and severe asthma in adults and adolescents. 14p. Available from: https:// ginasthma.org/gina-reports/. [accessed 2021 Jun 10]

57. Duong ML, Islam S, Rangarajan S, et al. Mortality and cardiovascular and respiratory morbidity in individuals with impaired FEV1(PURE): an international community-based cohort study. Lancet Glob Health. 2019;7:e613-23.

58. Panizza JA, James AL, Ryan G, Klerk ND, Finucane KE. Mortality and airflow obstruction in asthma: a 17-year follow-up study. Intern Med J. 2006;36(12): $773-80$.

59. Major S, Vezina K, Tse SM. Lung function of children following an intensive care unit admission for asthma. Pediatr Allergy Immunol Pulmonol. 2021;34(1):1-6.

60. O’Byrne P, Fabbri LM, Pavord ID, Papi A, Petruzzelli $S$, Lange P. Asthma progression and mortality: the role of inhaled corticosteroids. Eur Respir J. 2019;54:1900491.

61. Ekstrom S, Magnusson J, Kull, et al. Body mass index development and asthma throughout childhood. Am J Epidemiol. 2017;186(2):255-63.
62. Okoniewski W, Lu KD, Forno E. Weight loss for children and adults with obesity and asthma. A systematic review of randomized controlled trials. Ann Am Thorac Soc. 2019;16:613-25.

63. Ross KR, Gupta R, Deboer MD, et al. Severe asthma during childhood and adolescence: a longitudinal study. Allergy Clin Immunol. 2020;145:140-6 (e9).

64. Lavoie KL, Cartier A, Labrecque M, et al. Are psychiatric disorders associated with worse asthma control and quality of life in asthma patients? Respir Med. 2005;99:1249-57.

65. Bender BG. Risk taking, depression, adherence and symptom control in adolescents and young adults with asthma. Pulmonary Perspective. 2006;173: 953-7.

66. Gutierrez JL, Celedon JC. Chronic stress and asthma in adolescents. Ann Allergy Asthma Immunol. 2020;125(4):393-8.

67. Weinstein SM, Pugach O, Rosales G, Mosnaim GS, Walton SM, Martin MA. Family chaos and asthma control. Pediatrics. 2019;144(2): e20182758.

68. Booth-Laforce C, Kerns KA. Family influences on children's peer relationships. In: Rubin $\mathrm{KH}$, Bukowski W, Laursen B, editors. Peer interactions, relationships, and groups. New York: Guilford; 2009. p. 508-30.

69. Guo SE, Ratner PA, Johnson JL, Okoli CTC, Hossain S. Correlates of smoking among adolescents with asthma. J Clin Nurs. 2010;19(5-6):701-11.

70. Rasmussen F, Siersted HC, Lambrechtsen J, Hansen HS, Hansen NCG. Impact of airway lability, atopy and tobacco smoking on the development of asthma-like symptoms in asymptomatic teenagers. Chest. 2000;117:1330-5.

71. Lee JH, Haselkorn T, Borish L, Rasouliyan L, Chipps $\mathrm{BE}$, Wenzel SE. Risk factors associated with persistent airflow limitation in severe or difficult-to-treat asthma: insights from the TENOR study. Chest. 2007;132:1882-9.

72. Leung R, Wong G, Lau J, et al. Prevalence of asthma and allergy in Hongkong schoolchildren: an ISAAC study. Eur Respir J. 1997;10:354-60.

73. Jordao EA, Kuschnir FC, Figueiredo VC, et al. ERICA: smoking is associated with more severe asthma in Brazilian adolescents. J Pediatr (Rio J). 2019;95:538-44.

74. Wang TW, Gentke AS, Neff LJ, et al. Characteristics of e-cigarette use behaviours among US Youth, 2020. JAMA Netw Open. 2021;4(6): e2111336. 
75. King BA, Jones CM, Baldwin GT, Briss PA. The EVALI and youth vaping epidemics- implications for public health. N Engl J Med. 2020;382(8): 689-91.

76. Layden J, Ghinai I, Pray I, Kimball A, Layer M, Tenforde $\mathrm{M}$, et al. Pulmonary illness related to e-cigarette use in Illinois and Wisconsin- final report. N Engl J Med. 2020;382:903-16.

77. Centers for Disease Control and Prevention. Outbreak of lung injury associated with e-cigarette use, or vaping. United States: CDC. Available from: https://www.cdc.gov/tobacco/basic_information/ecigarettes/severe-lung-disease/healthcare-providers/ index.html. [Updated 2020 Feb]

78. Tang M, Lang JE. Smoking: it's still a big problem in children with asthma. J Pediatr (Rio J). 2019;95: 506-8.

79. Centers for Disease Control and Prevention. Preventing tobacco use among young people: a report of the Surgeon General. Atlanta: US Department of Health and Human Services, Public Health Service; 1994. (Office on Smoking and Health).

80. Fanshawe TR, Halliwell W, Lindson N, Aveyard P, Livingstone-Banks J, Hartmann-Boyce J. Tobacco cessation interventions for young people. Cochrane Database System Rev. 2017. https://doi.org/10. 1002/14651858.CD003289.pub6.

81. Booalayan H, Abdualrasool M, Al-Shanfari S, et al. Exposure to environmental tobacco smoke and prevalence of asthma among adolescents in a Middle Eastern country. BMC Public Health. 2020;20: 1210 .

82. Barua RS, Rigotti NA, Benowitz NL, et al. 2018 American College of Cardiology (ACC) expert consensus decision pathway on tobacco cessation treatment: a report of the ACA task force on clinical expert consensus documents. J Am Coll Cardiol. 2018;72(25):3332-65.

83. Difranza JR, Rigotti NA, McNeill AD, et al. Initial symptoms of nicotine dependence in adolescents. Tob Control. 2000;9:313-9.

84. Heatherton TF, Kozolowski LT, Frecker RC, Fagerstrom KO. The Fagerstrom test of nicotine dependence: a revision of the Fagerstrom Tolerance Questionnaire. Br J Addict. 1991;86(9):1119-27.

85. Pbert L, Flint AJ, Fletcher KE, Young MH, Druker S, DiFranza J. Effect of a pediatric practice-based smoking prevention and cessation intervention for adolescents: a randomized, controlled trial. Pediatr. 2008;121: e738.
86. Halpern SD, Harhay MO, Saulsgiver K, Brophy C, Troxel AB, Volpp KG. A pragmatic trial of e-cigarettes, incentives and drugs for smoking cessation. N Engl J Med. 2018;378:2302-10.

87. Casey BJ, Getz S, Galvan A. The adolescent brain. Dev Rev. 2008;28(1):62-77.

88. Roberts G, Vazquez-Ortiz M, Knibb R, et al. EAACI Guidelines on the effective transition of adolescents and young adults with allergy and asthma. Allergy. 2020;75:2734-52.

89. Transition and Patient Empowerment, Innovation, Education and Research (TIER) Network. Ready, Steady, Go program. Available from: https://www. readysteadygo.net/. [Accessed Sep 24, 2021]

90. Nagra A, McGinnitty PM, Davis N, et al. Implementing transition: ready steady go. Arch Dis Child Educ Pract Ed. 2015;100:313-20.

91. Scarponi D, Cammaroto V, Pasini A, et al. Multidisciplinarity in transition pathways for patients with kidney disease: the current state of play. Front Paediatr. 2021;9: 689758.

92. Colver A, Rapley T, Parr JR et al. Facilitating the transition of young people with long-term conditions through health services from childhood to adulthood: the Transition research programme. In: Programme Grants for Applied Research, 2019, no. 4, vol. 7, NIHR Journals Library, Southampton (UK).

93. Zhang LF, Ho JS, Kennedy SE. A systematic review of the psychometric properties of transition readiness assessment tools in adolescents with chronic disease. BMC Pediatr. 2014. https://doi.org/10.1186/ 1471-2431-14-4.

94. National Institute for Health and Care Excellence. Transition from children's to adults' services for young people using health or social care services. London. NICE. Published 2016. Available from: https://www.nice.org.uk/guidance/ng43/chapter/ Recommendations

95. Sawicki GS, Lukens-Bull K, Yin X, et al. Measuring the transition readiness of youth special healthcare needs: validation of the TRAQ-Transition Readiness Assessment Questionnaire. J Pediatr Psychol. 2011;36:160-71.

96. Price D, Bjermer L, Bergin DA, Martinez R. Asthma referrals: a key component of asthma management that needs to be addressed. J Asthma Allergy. 2017;10:209-23.

97. Viner R. Transition from pediatric to adult care. Bridging the gaps or passing the buck? Arch Dis Child. 1999;81(3):271-5. 
98. Persaud YK, Portnoy JM. Ten rules for implementation of a telemedicine program to care for patients with asthma. J Allergy Clin Immunol Pract. 2021;9: 13-21.

99. Car J, Koh GCH, Foong PS, Wang CJ. Video consultations in primary and specialist care during the COVID-19 pandemic and beyond. Brit Med J. 2020;371: m3945.

100. Fields BG. Regulatory, legal and ethical considerations of telemedicine. Sleep Med Clin. 2020;15(3): 409-16.

101. Coreas SI, Rodriquez EJ, Rahman SG, et al. Smoking susceptibility and tobacco media engagement among youth never smokers. Pediatrics. 2021;147(6): e2020017921.

102. US Food and Drug Administration. Newly signed legislation raises federal minimum age of sale of tobacco products to 21. United States, FDA. Available from: https://www.fda.gov/tobacco-products/ ctp-newsroom/newly-signed-legislation-raisesfederal-minimum-age-sale-tobacco-products- 21 . [updated 2020 Jan 15]

103. US Food and Drug Administration. The Real Cost Campaign. United States, FDA. Available from: https://www.fda.gov/tobacco-products/publichealth-education/real-cost-campaign. [updated 2021 Feb 26]

104. Farrelly MC, Niederdeppe J, Yarsevich J. Youth tobacco prevention mass media campaigns: past, present, and future directions. Tob Control. 2003;12(Suppl 1):i35-47.

105. Clark NM, Shah S, Dodge JA, Thomas LJ, Andridge RR, Little RJ. An evaluation of asthma interventions for preteen students. J Sch Health. 2010;80:80-7.
106. Kew KM, Carr R, Crossingham I. Lay-led and peer support interventions for adolescents with asthma. Cochrane Database Syst Rev. 2017;4: Cd012331.

107. Forero R, Bauman A, Young L, Booth M, Nutbeam D. Asthma, health behaviours, social adjustment and psychosomatic symptoms in adolescents. J Asthma. 1996;33(3):157-64.

108. Neuharth-Pritchett S, Getch Y. Asthma and the school teacher: the status of teacher preparedness and training. J Sch Nurs. 2001;17:323-8.

109. Bedosky L. Asthma tech to watch in 2020. Available from: https://www.everydayhealth.com/asthma/ asthma-tech-to-watch/. [published 2020 Feb 11]

110. Murray E, Burns J, Tai SS, Lai R, Nazareth I. Interactive health communication applications for people with chronic disease. Cochrane Database Syst Rev. 2005;4: Cd004274.

111. Ramsey RR, Plevinsky JM, Kollin SR, Gibler RC, Guilbert TW, Hommel KA. Systematic review of digital interventions for pediatric asthma management. J Allergy Clin Immunol Pract. 2020;8(4): 1284-93.

112. Himes BE, Leszinsky L, Walsh R, Hepner H, Wu AC. Mobile health and inhaler-based monitoring devices for asthma management. J Allergy Clin Immunol Pract. 2019;7(8):2535-43.

113. Georgiou M. Developing a healthcare app in 2021: what do patients really want? Available from: https://www.imaginovation.net/blog/developing-amobile-health-app-what-patients-really-want/. [Published 2021 Jan 23] 